\title{
Effect of $\mathrm{H}_{2}$ Exposure on $\mathrm{TiO}_{2}$-based Ceramic Thick Films
}

\author{
G. C. MATHER, F. M.B. MARQUES, J. R. FRADE
}

Departamento de Engenharia Cerâmica e do Vidro, UIMC, Universidade de Aveiro, 3810-193 Aveiro, Portugal

\begin{abstract}
Thick-film sensors based on $\mathrm{TiO}_{2}$ (anatase and rutile) and composites of $\mathrm{TiO}_{2}-\mathrm{Al}_{2} \mathrm{O}_{3}$ and $\mathrm{TiO}_{2}-\mathrm{Y}_{2} \mathrm{O}_{3}$ have been tested for their electrical response on exposure to $\mathrm{H}_{2}$. Film d.c. resistance was measured in the temperature range $500-650^{\circ} \mathrm{C}$ as a function of time and gas-phase composition (air, $\mathrm{N}_{2}$ and $10 \% \mathrm{H}_{2}$ in an $\mathrm{N}_{2}$-based stream); the equilibrium gas-phase $\mathrm{Po}_{2}$ was simultaneously monitored with a $\mathrm{ZrO}_{2}$-based oxygen sensor. The detection mechanism of $\mathrm{TiO}_{2}$ to $\mathrm{H}_{2}$ involves the formation of fully ionised oxygen vacancies for both anatase and rutile. The addition of $\mathrm{Al}_{2} \mathrm{O}_{3}$ and $\mathrm{Y}_{2} \mathrm{O}_{3}$ did little to affect film sensitivity at the tested $\mathrm{H}_{2}$ concentration levels.
\end{abstract}

Keywords: Electrical properties, $\mathrm{TiO}_{2}$, sensors, $\mathrm{H}_{2}$

Efecto de la exposición $\mathrm{A} \mathrm{H}_{2}$ sobre láminas gruesas cerámicas basadas en $\mathrm{TIO}_{2}$

Los sensores de lámina gruesa basados en $\mathrm{TIO}_{2}$ (Anatasa y rutilo) y materiales compuestos de $\mathrm{TiO}_{2}-\mathrm{Al}_{2} \mathrm{O}_{3}$ y $\mathrm{TiO}_{2}-\mathrm{Y}_{2} \mathrm{O}_{3}$ han sido evaluados en función de su respuesta eléctrica a la exposición de $\mathrm{H}_{2}$. La resistencia d.c. de las láminas fue medida en el rango de temperaturas de $500-560^{\circ} \mathrm{C}$ en función del tiempo y la composición de la fase gaseosa (aire, $\mathrm{N}_{2}$ y $10 \%$ H $\mathrm{H}_{2}$ en un vapor basado en $\mathrm{N}_{2}$ ); el equilibrio de $\mathrm{PO}_{2}$ de la fase gaseosa fue simultanemente monitorizado con un sensor de oxígeno basado en $\mathrm{ZrO}_{2}$. El mecanismo de detección del $\mathrm{H} 2$ por el $\mathrm{TiO}_{2}$ incluye la formación de vacantes de oxígeno totalmente ionizadas por la anatasa y el rutilo. La adición de $\mathrm{Al}_{2} \mathrm{O}_{3} \mathrm{y} \mathrm{Y}_{2} \mathrm{O}_{3}$ apenas afecta la sensibilidad de la lámina en los niveles de $\mathrm{H} 2$ evaluados.

Palabras clave: propiedades eléctricas $\mathrm{TIO}_{2}$, sensores, $\mathrm{H}_{2}$

\section{INTRODUCTION}

Recent studies on ceramic-oxide gas sensors have focused on the use of $\mathrm{TiO}_{2}$ (anatase) as a $\mathrm{CO}$ and $\mathrm{H}_{2}$ sensor with uses such as the detection of potentially explosive gas leaks in industrial processes and to indicate the efficiency of hydrocarbon combustion $(1,2)$. The mechanism for detection of reducing gases in simple binary metal oxides, most commonly $\mathrm{SnO}_{2}$, has been ascribed to a change in the concentration of chemisorbed surface oxygen at the semiconductor surface, commonly forming the species $\mathrm{O}_{2}^{-}$and creating a potential barrier between grains $(3,4)$. The reducing gas depletes the coverage of adsorbed oxygen ions and supplies electrons to the conduction band; in n-type semiconductors, such as $\mathrm{TiO}_{2}$, this is accompanied by a fall in resistance. However, we have recently shown that in the case of $\mathrm{TiO}_{2}$ (anatase), the electrical response of the sensor is a function of the oxygen partial pressure rather than direct interaction of $\mathrm{H}_{2}$ with the titania film (5). The detection mechanism for $\mathrm{H}_{2}$ may, thus, be interpreted as involving the formation of fully ionised oxygen vacancies. Measurements with both Pt and Au electrodes indicated that, in the measured temperature range $\left(500-650^{\circ} \mathrm{C}\right)$ there was no catalytic surface effect and that the equilibration of the film with the surrounding $\mathrm{Po}_{2}$ environment involved a bulk effect. It had previously been reported that the response time of anatase to $\mathrm{H}_{2}$ exposure is much slower than to $\mathrm{CO}$ exposure. This can be explained as resulting from surface- and bulk-controlled sensing mechanisms for $\mathrm{CO}$ and $\mathrm{H}_{2}$, respectively.

A current trend in sensor research is to attempt to improve the selectivity and sensitivity of the ceramic oxide by elimina- ting similar responses from interfering gases (6). In the case of anatase, where we have shown that the detection mechanism of $\mathrm{H}_{2}$ is a bulk effect, it may be possible to exploit the difference in detection mechanism with other reducing gases to achieve this aim. One way in which this may be brought about is by the addition of secondary oxide phases or elemental metals. A recent study has shown the effects of a second insulating phase on the sensing properties of anatase: it is reported that the addition of $10 \mathrm{wt} . \% \mathrm{Y}_{2} \mathrm{O}_{3}$ resulted in an increase in sensitivity to $\mathrm{CO}$ and decreased sensitivity to $\mathrm{H}_{2}$, whereas the effect of $10 \mathrm{wt} \% \mathrm{Al}_{2} \mathrm{O}_{3}$ was to cause the sensor to respond to $\mathrm{H}_{2}$ alone (6).

In this paper, we extend our previous work of the effects of $\mathrm{H}_{2}$ exposure on the electrical behaviour of $\mathrm{TiO}_{2}$ (anatase) to include the rutile polymorph of $\mathrm{TiO}_{2}$ and to determine the effects of the addition of $10 \mathrm{wt} \% \mathrm{Al}_{2} \mathrm{O}_{3}$ and $10 \mathrm{wt} \% \quad \mathrm{Y}_{2} \mathrm{O}_{3}$ on both of these $\mathrm{TiO}_{2}$ polymorphs. The resistance of thick-film samples of the above compositions is measured at series of temperatures in the range $500-650^{\circ} \mathrm{C}$ as a function of time, gas phase composition and oxygen partial pressure.

\section{EXPERIMENTAL}

Experimental details, including a detailed description of the measuring system, are given in Ref. (5); only a brief description of the experimental procedure is, therefore, given here. Thick-film sensors of the anatase and rutile polymorphs of 
$\mathrm{TiO}_{2}$ and $\mathrm{TiO}_{2}-10$ wt. $\% \mathrm{Al}_{2} \mathrm{O}_{3}, \mathrm{TiO}_{2}-10 \mathrm{wt}$. $\% \mathrm{Y}_{2} \mathrm{O}_{3}$ composites were prepared on $\mathrm{Al}_{2} \mathrm{O}_{3}$ substrates by screen printing. In the case of the anatase and anatase-composite materials, the wet films were dried, fired at $800^{\circ} \mathrm{C}$ for 1 hour then cooled to room temperature. A similar routine was performed with the rutile and rutile- $\mathrm{Al}_{2} \mathrm{O}_{3}$ film, but with final firing at $1200^{\circ} \mathrm{C}$. For the rutile- $\mathrm{Y}_{2} \mathrm{O}_{3}$ composite, the film was fired at $900^{\circ} \mathrm{C}$ since, above this temperature, significant amounts of $\mathrm{Y}_{2} \mathrm{Ti}_{2} \mathrm{O}_{7}$ were formed. Electrical contacts were provided by two strips of Pt paste on the sensor surface separated by approximately $4 \mathrm{~mm}$; the organic matter was removed from the paste after application by firing for a short time at $800^{\circ} \mathrm{C}$. The anatase and rutile polymorphs of $\mathrm{TiO}_{2}$ and the unreactivity of the additional oxides were confirmed after firing by X-ray diffraction (XRD).

The test system consisted of the sensor attached to a pressure mount in a sealed vertical tube furnace with a $\mathrm{ZrO}_{2}$-based oxygen sensor placed close to the sensor surface in order to determine oxygen partial pressure. A gas-flow meter (Bronkhurst $\mathrm{Hi}-\mathrm{Tec}$ ) supplied a constant gas-flow rate of 50 $\mathrm{ml} / \mathrm{min}$ from $\mathrm{N}_{2}$ and $10 \% \mathrm{H}_{2}$ in $\mathrm{N}_{2}$ gas lines; a line of compressed air could also be supplied to the furnace. The electrical response of the sensor could be measured by both a.c. impedance (H.P. 4284A a.c. impedance analyser working in the frequency range $20 \mathrm{~Hz}-1 \mathrm{MHz}$ ) and d.c. methods (Fluke 45 multimeter); the oxygen sensor electromotive force (emf) was measured with a Fluke 45 multimeter. Both multimeters were computer-controlled in order that the oxygen partial pressure and film resistance could be measured simultaneously.

\section{RESULTS AND DISCUSSION}

Test runs involved measuring the sensor resistance and oxygen sensor emf through a series of gas changes. The furnace was flushed with air for a short period then $\mathrm{N}_{2}$ for approximately 1 hour to ensure that the sample environment was as free of $\mathrm{O}_{2}$ as possible; the $\mathrm{H}_{2} / \mathrm{N}_{2}$ mixture was then introduced into the furnace chamber. The same procedure was repeated for all samples, throughout the range of measured temperatures $\left(500-650^{\circ} \mathrm{C}\right)$, to ensure conditions were as equivalent as possible for every run. However, faithful reproducibility of the sensor response between air and reducing conditions was not fully attainable due to long-term drift of the sensor resistance.

The information obtained from a.c. impedance spectra was limited: in air, the cell impedance was in the $M \Omega$ range, close to the upper limit of the machine operating range. Furthermore, the relaxation frequencies of the impedance arcs were quite low, which meant that the definition of the arcs was poor and limited to the high frequency part of the entire spectrum (Figure 1). Under highly reducing conditions $\left(10 \% \mathrm{H}_{2}+\right.$ $90 \% \mathrm{~N}_{2}$ ) and at lower temperatures, however, the cell impedance approached resistance values $(\sim 10 \mathrm{~kW})$ where the $Z^{\prime}-Z^{\prime \prime}$ plot was characterised by a single semicircle, which was depressed to a degree depending on the film composition. However, depression angles were small in every case. Figure 1 shows typical examples of the impedance spectra of anatasealumina and rutile films at $500^{\circ} \mathrm{C}$ in air and in an $\mathrm{H}_{2} / \mathrm{N}_{2}$ atmosphere. As mentioned previously there was no evidence for possible deconvolution of spectra into contributions with physical meaning. Hence, the majority of the electrical measurements were carried out using d.c. techniques.
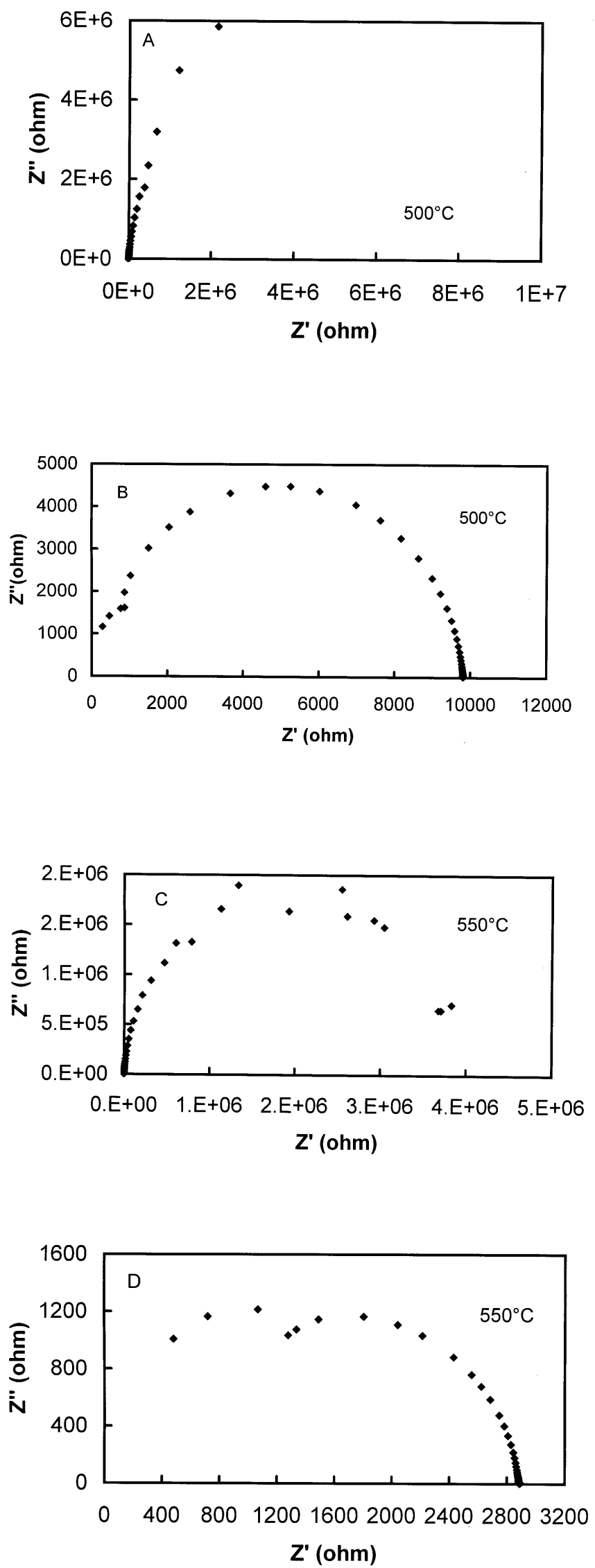

Fig 1. Impedance spectra of rutile (A, B) and anatase- $10 \mathrm{wt} \%$ alumina (C, D) thick-films at $500-550^{\circ} \mathrm{C}$ in air and in an $10 \% \mathrm{H}_{2}+90 \% \mathrm{~N}_{2}$ atmosphere, respectively. 

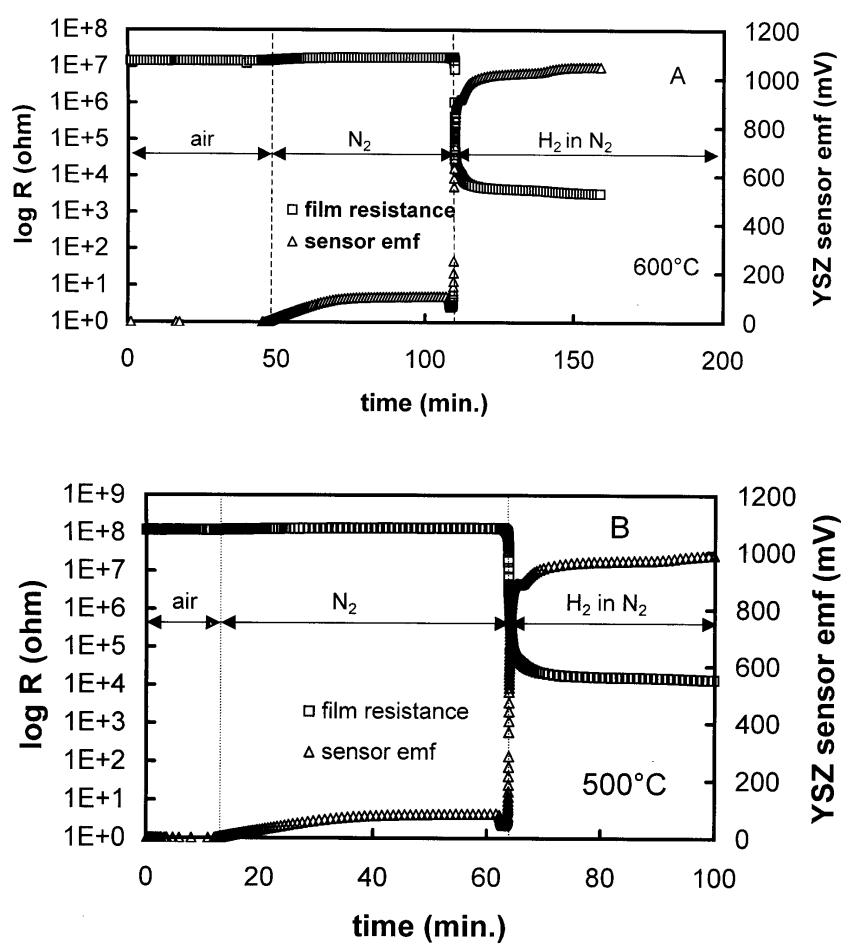

Fig 2. Log of film resistance ( $\log \mathrm{R})$ and YSZ oxygen sensor (emf) response of rutile (A), rutile-10wt\% yttria (B) and anatase-10wt $\%$ yttria (C) thick-film sensors at $500-600^{\circ} \mathrm{C}$, when the furnace atmosphere is flushed firstly with air, then $\mathrm{N}_{2}$ and finally $10 \% \mathrm{H}_{2}+90 \% \mathrm{~N}_{2}$.

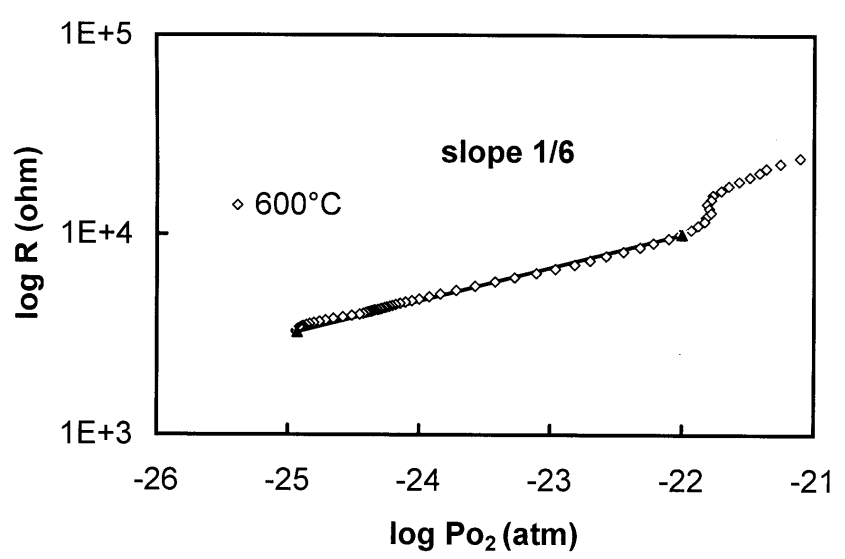

Fig 3. Plot of the $\log$ of a rutile sensor resistance (log R) against $\log$ of the oxygen partial pressure $\left(\log \mathrm{Po}_{2}\right)$ at $600^{\circ} \mathrm{C}$.

\subsection{Anatase and Rutile}

The $\mathrm{TiO}_{2}$ sensor response and corresponding YSZ sensor emf response on changing the gas atmosphere (air $\rightarrow \mathrm{N}_{2} \rightarrow$ $\mathrm{N}_{2}+\mathrm{H}_{2}$ ) is very similar for both anatase and rutile $\mathrm{TiO}_{2}$ polymorphs. Figure 2 shows the rutile resistance and $\mathrm{O}_{2}$ sensor emf at $600^{\circ} \mathrm{C}$ for such a cycle. In air, the $\mathrm{ZrO}_{2}$-based oxygen sensor emf is zero and the film resistance is very large $(\sim \mathrm{MW})$. After approximately 50 minutes, the air is cut off and $\mathrm{N}_{2}$ is introduced; the oxygen sensor emf correspondingly increases to $\sim 100$ $\mathrm{mV}$, but the film resistance remains in the MW range. When $10 \% \mathrm{H}_{2}$ is introduced into the $\mathrm{N}_{2}$ flow, after approximately 110 mins., there is a sudden decrease in both the film resistance (to a few $\mathrm{kW}$ ) and oxygen partial pressure ( the oxygen sensor emf increases to $\sim 1 \mathrm{~V})$. The emf and resistance curves change in a reciprocal fashion on introducing $\mathrm{H}_{2}$, as previously described for the anatase sensor. The rutile and anatase polymorphs showed similar behaviour, although the time required for the rutile film resistance to stablilise in $\mathrm{N}_{2}$ was somewhat longer than for the anatase films.

We have previously shown that, for anatase, the sensor resistance $(\mathrm{R})$ and gas-phase equilibrium oxygen partial pressure $(\mathrm{mV})$ display an almost linear log-log plot with a gradient of approximately $+1 / 6$ (see Ref. (5)). It can be seen in Fig. 3 that rutile has a similar $\log (\mathrm{R})$ vs. $\log \left(\mathrm{Po}_{2}\right)$ plot. Deviations from the $1 / 6$ gradient for higher values of $\mathrm{Po}_{2}$ ( $>10^{-22} \mathrm{~atm}$.) may be explained by sensor limitations, as discussed elsewhere $(5,7)$. Only the very low $\mathrm{Po}_{2}$ range is, therefore, shown in Fig. 3 in order to avoid the intermediate $\mathrm{Po}_{2}$ range where the $\mathrm{ZrO}_{2}$ based sensor is affected by these limitations. In previous work, we have shown that a gradient of $+1 / 6$ in the log (R) vs. log $\left(\mathrm{Po}_{2}\right)$ plot can be attributed to n-type conductivity associated with the formation of fully ionised oxygen vacancies in accordance with the following equilibrium:

$$
\mathrm{O}_{\mathrm{o}}^{\mathrm{x}} \Leftrightarrow 1 / 2 \mathrm{O}_{2}+\mathrm{V}_{\mathrm{o}}^{\bullet \bullet}+2 \mathrm{e}^{\prime}
$$

(Kröger-Vink notation). A simplified electroneutrality condition

$$
\mathrm{n}=2 \cdot\left[\mathrm{V}_{\mathrm{o}}^{\bullet \bullet}\right]
$$

involving such oxygen-defect formation can be combined with the thermodynamic equilibrium constant:

$$
\mathrm{K}=\mathrm{n}^{2} \cdot \mathrm{Po}_{2}{ }^{1 / 2} \cdot\left[\mathrm{V}_{\mathrm{o}}^{\bullet \bullet}\right]
$$

to give $\mathrm{n} \propto \mathrm{Po}_{2}{ }^{-1 / 6}$ and $\mathrm{R} \propto \mathrm{Po}_{2}{ }^{1 / 6}$. A gradient of $+1 / 6$ in the $\log \left(\mathrm{Po}_{2}\right)$ vs. $\log (\mathrm{R})$ plot is, thus, consistent with semiconductivity associated with formation of oxygen defects, assuming bulk equilibrium between the sensor film and surrounding atmosphere.

There appears to be little difference in the behaviour of the anatase and rutile forms of $\mathrm{TiO}_{2}$. Previous reports of $\mathrm{TiO}_{2}$ as hydrogen sensor concentrate exclusively on the anatase polymorph. Our studies were conducted on films with both structural forms since the rutile polymorph is considered the more stable phase and the higher firing temperature required for its formation affords a stronger subtrate-film contact. In order to test the long-term stability of the rutile phase at the sensor operating temperature, a sample of rutile was fired for a period of 5 months at $500^{\circ} \mathrm{C}$. Figure 4 shows that no evidence of the anatase polymorph was observed by XRD after this time. This indicates that the rutile form of $\mathrm{TiO}_{2}$ is stable at the sensor operating temperature and could be used as an alternative $\mathrm{H}_{2}$ sensor to anatase with the advantage of obtaining mechanically stronger devices than is possible with the anatase form due to the higher temperature at which rutile can be fired.

One final comment is required to address the apparent lack of response of the titania-based sensors when the atmosphere is changed from air to $\mathrm{N}_{2}$. While the $\mathrm{ZrO}_{2}$-based sensor clearly shows that the equilibrium $\mathrm{Po}_{2}$ dropped by approximately two orders of magnitude, the thick-film resistance seems to be insensitive to this change, contrary to the prediction of the model mentioned previously. Titania is a well known p-type conductor in air and an n-type conductor under reducing conditions. The change from p-type to n-type is known to occur 


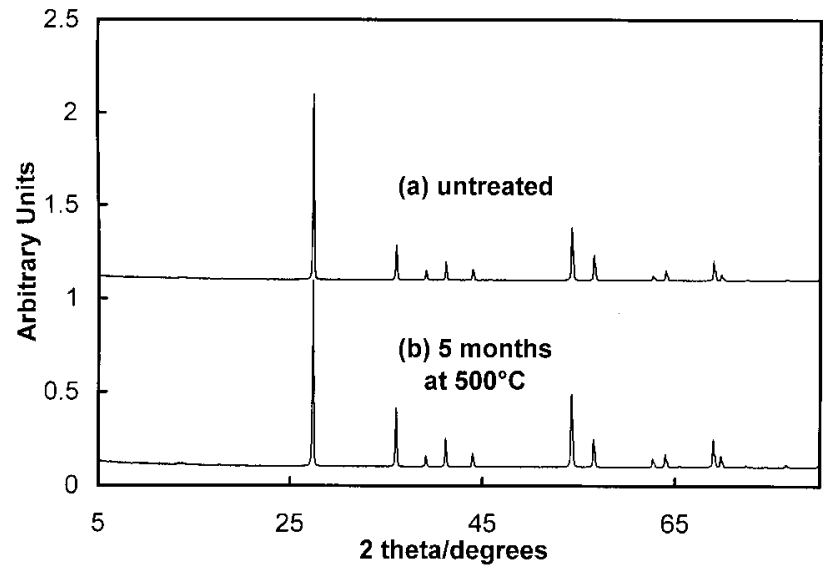

Fig. 4. XRD patterns of (a) rutile with no thermal treatment, (b) rutile annealed at $500^{\circ} \mathrm{C}$ for a period of 5 months.

under slightly oxidizing conditions in the range $500-700^{\circ} \mathrm{C}(8)$. Because of this, the sum of the p-and n-type conductivity contributions is almost constant within a limited range of $\mathrm{Po}_{2}$ (from air to about $10^{-3} \mathrm{~atm}$ ). This constancy of conductivity in this range explains the apparent insensitivy of the sensor to the change from air to $\mathrm{N}_{2}$. Furthermore, a change of about two orders of magnitude is much smaller than the change of more than 20 orders of magnitude $\left(\mathrm{Po}_{2}\right.$ decreases to values lower than $10^{-20}$ atm as shown in Figures 3 and 5) which is registered when $\mathrm{H}_{2}$ is introduced into the furnace. The relative magnitude of the titania sensor response should therefore be considerably different under each atmosphere change, which is the case.

\section{2. $\mathrm{Al}_{2} \mathrm{O}_{3}$ - and $\mathrm{Y}_{2} \mathrm{O}_{3}-\mathrm{TiO}_{2}$ Composites}

Films of 10wt. $\% \mathrm{Al}_{2} \mathrm{O}_{3}$-anatase, 10wt. $\% \mathrm{Al}_{2} \mathrm{O}_{3}$-rutile, 10wt.\% $\mathrm{Y}_{2} \mathrm{O}_{3}$-anatase and 10wt. $\% \mathrm{Y}_{2} \mathrm{O}_{3}$-rutile were similarly tested for sensor resistance and oxygen partial pressure through the series of gas atmospheres: air $\rightarrow \mathrm{N}_{2} \rightarrow 10 \% \mathrm{H}_{2}$ in $\mathrm{N}_{2}$. The behaviour of all the composite films was similar to that of the pure $\mathrm{TiO}_{2}$ films; no evidence was provided for the addition of a second phase altering the film sensitivity to hydrogen. Typical examples of data obtained with $10 \mathrm{wt} . \% \quad \mathrm{Y}_{2} \mathrm{O}_{3}$-anatase and 10wt. $\% \mathrm{Y}_{2} \mathrm{O}_{3}$-rutile films are also presented in Figure 2. Figure 5 shows the $\log \left(\mathrm{Po}_{2}\right)$ vs. $\log (\mathrm{R})$ plot at a series of temperatures for the composition 10wt. $\% \mathrm{Y}_{2} \mathrm{O}_{3}$-rutile. Again, the gradient of the slope at each temperature is $+1 / 6$, indicating that the hydrogen detection mechanism involves the formation of oxygen vacancies. Although we did not observe any detectable difference between the single-phase and composite films in terms of the response time or magnitude of the resistance change on hydrogen exposure, it should be noted that our experiments involved a rather large concentration of hydrogen $\left(10 \% \mathrm{H}_{2}\right.$ in $\left.\mathrm{N}_{2}\right)$; previous reports of the effect of second phases relate to much smaller hydrogen levels (ppm range).

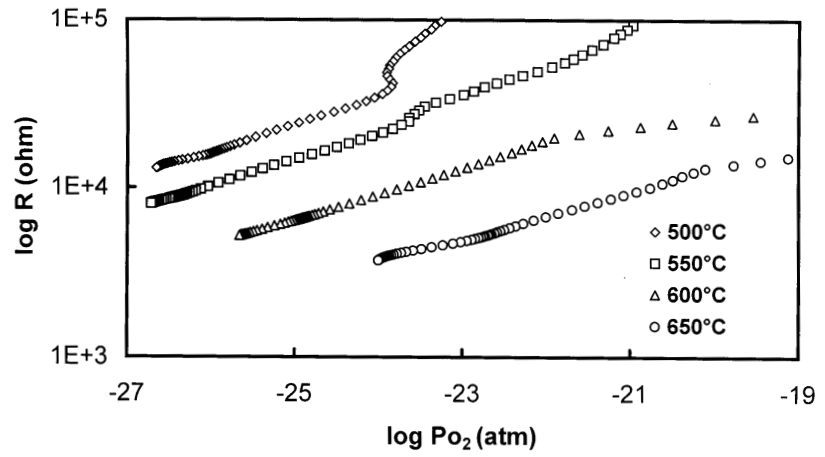

Fig. 5. Log of film resistance (log R) and YSZ oxygen sensor (emf) response of a rutile- $\mathrm{Y}_{2} \mathrm{O}_{3}$ composite thick-film sensor in the temperature range $500-600^{\circ} \mathrm{C}$.

\section{CONCLUSIONS}

The detection mechanism of $\mathrm{TiO}_{2}$ to hydrogen involves the formation of fully ionised oxygen vacancies for both anatase and rutile $\mathrm{TiO}_{2}$ polymorphs, as indicated by a gradient of $+1 / 6$ for the $\log (\mathrm{R})$ versus $\log \left(\mathrm{Po}_{2}\right)$ plots at a series of temperatures in the range $500-650^{\circ} \mathrm{C}$. The similarity in behaviour of the two modifications suggests that rutile may be a more suitable candidate for sensor fabrication since it is the more stable form and provides a stronger substrate-film contact. The addition of 10wt. $\% \mathrm{Al}_{2} \mathrm{O}_{3}$ or $10 \mathrm{wt}$. $\% \mathrm{Y}_{2} \mathrm{O}_{3}$ to each of the polymorphs did little to affect the film sensitivity at the levels of hydrogen concentration which were tested $\left(10 \% \mathrm{H}_{2}\right.$ in $\left.\mathrm{N}_{2}\right)$. Composite films were also shown to detect hydrogen by the formation of fully ionised oxygen vacancies.

\section{ACKNOWLEDGEMENT}

Financial support from FCT (PRAXIS programme) is greatly appreciated.

\section{REFERENCES}

1. A.-M. Azad, S. Akbar and L. Younkman, Ceramic sensors for carbon monoxide and hydrogen, The Electrochemical Society Interface, 37, 31-34 (1994)

2. S.A. Akbar and L.B. Younkman, Sensing mechanism of a carbon monoxide sensor based on anatase titania, J. Electrochem. Soc., 144 1750-1753 (1997).

3. H. Windischmann and P. Mark, A Model for the Operation of a Thin-Film $\mathrm{SnO}_{\mathrm{x}}$ Conductance-Modulation Carbon Monoxide Sensor, J. Electrochem. Soc., 126, 627-633 (1979).

4. P.T. Moseley, Materials selection for semiconductor gas sensors, Sensors and Actuators B, 6, 149-156 (1992).

5. G.C. Mather, F.M.B. Marques and J.R. Frade, Detection mechanism of $\mathrm{TiO}_{2}$ Based Ceramic $\mathrm{H}_{2}$ Sensors, J. Eur. Ceram. Soc., 19, 887-891 (1999).

6. L.D. Birkefeld, A.-M. Azad and S.A. Akbar, Carbon Monoxide and Hydrogen Detection by Anatase Modification of Titanium Dioxide, J. Am. Ceram. Soc., 75(11) , 2964-2968 (1992).

7. F.M.B. Marques and G.P. Wirtz, Oxygen Fugacity Control in Nonflowing Atmospheres: I, Experimental Observations in $\mathrm{CO} / \mathrm{CO}_{2}$ and $\mathrm{O}_{2} / \mathrm{N}_{2}$ Mixtures, J. Am. Ceram. Soc., 75(2) , 369-374 (1992).

8. E.M. Logothethis, Resistive-type exhaust gas sensors, Ceramic Engineering and Science Proceedings, 1, 281-301 (1981). 